\title{
ĐÁNH GIÁ KẾT QUẢ PHẪU THUÂTT KẾT XƯƠNG BÊN TRONG Ở BÊNH NHÂN GÃY KÍN DUPUYTREN TẠI BỆNH VIỆN TRUNG ƯƠNG QUÂN ĐộI 108
}

\begin{abstract}
Nguyễn Văn Lượng*, Nguyễn Điện Thành Hiệp*
TÓM TẮT

Mục tiêu: Gãy Dupuytren là một tổn thương đăc biệt vững cổ chân, là một tổn thương thường gặp trển lâm sàng. Mục tiêu của nghiên cứu này là đánh giá kết quả kết xương bên trong của loại gãy này. Đối tượng và phương pháp: 38 BN gãy kín Dupuytren, được phẫu thuật kết xương bên trong từ 9/2015-6/2020 tại Bệnh viện TWQĐ 108. Có 22 nam và 16 nữ, tuổi trung bình 46,26 tuổi (22-72), trong đó gãy ở chân trái là 23 BN, gãy chân phải là 15 BN. Nguyên nhân tổn thương là TNGT gặp ở $20 \mathrm{BN}$, do TNLĐ gặp ở $2 \mathrm{BN}$, do ngã gặp ở 13 BN, do TNTT gặp ở 3 BN. Đánh giá kết quả dựa theo bảng điểm đánh giá chức năng khớp cổ chân của Hiệp hội chỉnh hình cổ chân, bàn chân Hoa Kỳ (AOFAS). Kết quả: 20 BN gãy 3 mắt cá, 17 BN gãy 2 mắt cá, $1 \mathrm{BN}$ gãy mắt cá ngoài đơn thuân. Có $2 \mathrm{BN}$ gãy loại I, 8 BN gãy loại II, 4 BN gãy loại III, 2 BN gãy loại IV theo phân loại gãy mắt cá sau của Bartonicek. Có 23 BN gãy kiểu Weber $B$ và $15 B N$ kiểu Weber $C$. Đánh giá sau mổ 6 tháng trên 34 BN tái khám, điểm AOFAS trung bình là 91,79 . Kết quả khá đến tốt đạt được ở 32/34 BN, có 2 BN kết quả trung bình $(5,9 \%)$

and falling injury in 13 patients, sports injury in 3 patients. Evaluate the results based on the American Orthopedics Foot and Ankle Society (AOFAS) AnkleHindfoot Score. Results: 20 patients had triple trimalleolar fractures. 17 patients had bimalleolar fractures and 1 patient had simple lateral malleolar fracture. There were 2 patients with type I fracture, 8 patients with type II fracture, 4 patients with type III, 2 patients with type IV fracture according to the Bartonicek classification of posterior malleolus fracture. There were 23 patients with type B and 15 patients with type $\mathrm{C}$ according to the Weber classification of malleolus fracture. Evaluation after 6 months on 34 patients re-examined. The average AOFAS score is 91.79. Good to excellent results in 32 patients, there were 2 patients with average results accounting for $5.9 \%$ and no patients with poor results. Superficial infection occurred in 3 patients, $100 \%$ of the patients had anatomic X-ray images after surgery. Conclusions: Internal fixation for anatomical structures and functions of ankles were well restored in malleolar fractures.
\end{abstract} và không có $B N$ kết quả xấu. Có $1 B N$ nhiễm trùng nông vết mổ, $100 \%$ BN có hình ảnh XQ đạt giải phẫu sau mổ. Kết luận: Kết hợp xương bển trong là phương pháp điều trị đat hiệu quả cao, giúp BN phục hồi lại được hình thể giải phẫu và chức năng khớp cổ chân. mắt cá

Tư khóa: Gãy Dupuytren, gãy 2 mắt cá, gãy 3

\section{SUMMARY}

EVALUATION OF RESULTS OF INTERNAL OSTEOSYNTHESIS OF PATIENTS WITH CLOSED DUPUYTREN FRACTURE TREATED IN 108 CENTRAL MILITARY HOSPITAL

Objective: Dupuytren fracture is a special type of ankle's injury which are popular in clinic. The aim of this study is to evaluate the results of surgical treatment of these fractures. Patients and methods: The data of 38 patients with closed Dupuytren fracture from September 2015 to June 2020, who were treated with open reduction and internal fixation in the 108 Central Military Hospital were analyzed. There were 22 males and 16 females, the average age was 46.26 years (range, 22 to 72 years), the fractures occurred on the left side in 23 patients and on the right side in 15 patients. The cause of injuries were traffic accidents in 20 patients, labor accident in 2 patients,

*Bênh viên TUQQĐ 108

Chịu trách nhiệm chính: Nguyễn Văn Lượng

Email: luongnv108@gmail.com

Ngày nhận bài: 18/8/2021

Ngày phản bienj khoa học: 10/9/2021

Ngày duyệt bài: 1/10/2021
Keywords: Dupuytren fracture, bimalleolar fracture, trimalleolar fracture.

\section{I. ĐĂT VẤN ĐỀ}

Gãy Dupuytren là một dạng gãy xương vùng cổ chân với thương tổn đặc trưng là: gãy mắt cá trong (MCT) hoặc đứt dây chằng Delta; gãy mắt cá ngoài $(\mathrm{MCN})$, doãng mộng chày mác và đứt dây chằng chày mác dưới, xương sên bán trật khớp ra ngoài, nếu có gãy mắt cá sau (MCS) thì kèm theo bán trật khớp xương sên ra sau. Các thương tổn này làm mất sự vững chắc của khớp chày sên - một khớp chịu sức nặng của toàn cơ thể khi đi lại. Nếu xương sên bị trật ra ngoài 1 $\mathrm{mm}$ thì diện tích tiếp xúc với xương sên của khỡp chày sên sẽ giảm đi $42 \%$ [1], điều này sẽ dẫn đến thoái hóa sớm khớp chây sên. Chẩn đoán các tổn thương trong gãy Dupuytren dựa trên khám lâm sàng, XQ, CT-Scanner. Phẫu thuật nắn chỉnh mở và kết hợp xương bên trong ngày càng phổ biến với mục đích nắn chỉnh phục hồi lại giải phẫu và cố định ổ gãy xương, phục hồi vị trí giải phẫu của xương sên, cố định lại khớp chây mác dưới, giúp BN vận động phục hồi chức năng sớm và tránh các di chứng chấn thương. Trên thế giới đã có nhiều công trình nghiên cứu về gãy các mắt cá nói chung và gãy Dupuytren nói riêng, tuy nhiên vẫn còn chưa thống nhất về kỹ thuật bắt vít cố định mộng chày mác, chỉ định và kỹ thuật kết xương mắt cá sau [2], [3], [4]...Ở Việt 
Nam cũng có một số tác giả báo cáo về kết quả điêu trị kết xương Dupuytren tuy nhiên chưa có nghiên cứu sâu về điều trị gãy Dupuytren khi có gãy mắt cá sau kèm theo. Vì vậy, chúng tiến hành nghiên cứu đề tài: "Đánh giá kết quả phẫu thuật kết xương bên trong ở BN gãy kín Dupuytren tại Bệnh viện Trung ương Quân đội 108" nhằm muc đích:

- Đánh giá kêt quả điều trị phẫu thuật kêt xương bên trong gãy Dupuytren

- Rút ra một số nhận xét vè chi định, kỹ thuật mổ.

II. ĐỐI TƯỢNG VÀ PHƯƠ'NG PHÁP NGHIÊN CỨU

2.1. Đối tượng: $38 \mathrm{BN}$ gãy kín Dupuytren được phẫu thuật kết xương bên trong tại khoa Chấn thương chỉnh hình tổng hợp Bệnh viện TWQĐ 108, từ 9/2015 đến 6/2020.

Tiêu chuẩn lựa chọn: $B N$ được chẩn đoán gãy kín Dupuytren: Gãy xương mác ở vị trí $1 / 3$ dưới hoặc đâu dưới xương mác, có doãng mộng chày mác, bán trật khớp xương sên ra ngoài, có gãy mắt cá trong hoặc đứt dây chằng Delta. Tuổi từ 18 tuổi trở lên, đã được kết xương bên trong.

Tiêu chuẩn loại trừ: Gãy xương bệnh lý, gãy xương ở chi sẵn có dị tật, di chứng.

2.2. Phương pháp: Mô tả cắt ngang, kết hợp hồi cứu và tiến cứu. Cõ̃ mẫu thuận tiện.

Quy trình phẫu thuật.

- Vô cảm: gây tê tủy sống hoặc gây mê nội khí quản.

- Ga rô 1/3 dưới đùi.

Tóm tắt kỹ thuật phẫu thuật:

- Tư thế BN, đường mổ:

+ Nếu không có gãy mắt cá sau: $\mathrm{BN}$ nằm ngửa.

+ Nếu có gãy mắt cá sau: $B N$ nằm sấp, kê cao cổ chân.

- Thì kết xương mác: Ổ gãy xương mác được nắn chỉnh thẳng trục, và chỉnh hết di lệch chồng, xoay. Xương mác được cố định vững chắc bằng nẹp vít lòng máng với các vít xương cứng $3.5 \mathrm{~mm}$.

- Thì kết xương mắt cá trong: Kết xương mắt cá trong bằng hai vít xốp.

- Gãy mắt cá sau: Kết xương với đường mổ sau ngoài hoặc sau trong cùng với kết xương mắt cá trong hoăc mắt cá ngoài.

- Cố định khớp chày mác dưới: Sau khi cố định vững chắc ổ gãy xương mác và mắt cá sau (nễu có). Thời gian giữ vít khoảng 8 đến 10 tuần.

- Thì đóng vết mổ: Bơm rửa, khâu phục hồi lại dây chằng, bao khớp, cầm máu, dẫn lưu (nếu cần).

Chăm sóc sau mổ: $B N$ được cố định nẹp chỉnh hình cẳng bàn chân, bàn chân ở tư thế trung bình, gác cao chân nếu sưng nề nhiều. Thăy băng hàng ngày, rút dẫn lưu (nếu có) sau 48h. Điều trị kháng sinh dự phòng, kết hợp giảm đau, chống phù nề. Cắt chỉ sau mổ 14 ngày.

Tập phục hồi chức năng: Tập vận động khớp gối, khớp háng và những chi khổng phải bất động ngay sau mổ.

Theo dõi sau mổ: Hen BN sau mổ 8 - 10 tuần đến mổ tháo vít cố định khớp chày mác dưới. BN được khám lại vào các thời điểm sau 1 , 3,6 tháng và 12 tháng.

\subsection{Các chỉ tiêu nghiên cứu:}

Đặc điểm BN: Tuổi, giới, vị trí, nguyên nhân, cơ chế chấn thương, tổn thương giải phẫu bênh, cơ chế chấn thương (theo Lauge - Hansen gồm: ngửa- khép, ngửa- xoay ngoài, sấp- dạng, sấp- xoay ngoài, phân loại tổn thương mắt cá theo Danis- Weber, phân loại gãy mắt cá sau theo Bartonicek, thời điểm phẫu thuật, phương pháp phẫu thuâat, thời gian nằm viện.

Kết quả gần: Diễn biến tại vết mổ, kết quả kết xương sau mổ.

Kết quả xa: Bao gồm kết quả về chức năng và kết quả về $X Q$ khớp cổ chân.

- Kết quả chức năng được đánh giá dựa theo bảng điểm đánh giá chức nắng khớp cổ chân của Hiệp hội chỉnh hình cổ chân, bàn chân Hoa Kỳ (AOFAS). - Kết quả về XQ: Tỷ lệ liền xương, khớp giả, liền lệch, doãng mộng chày mác, thoái hóa khớp cổ chân.

- Tai biến, biến chứng

2.4. Xử lý số liệu: Sau khi thu thập thông tin sẽ được xử lý bằng phần mềm SPSS 20.0.

\section{KẾT QUẢ NGHIÊN CỨU}

3.1. Đặc điểm dịch tễ. 22 BN nam $(57,9 \%)$ và nữ có $16 \mathrm{BN}(42,1 \%)$. Tuổi trung bình 46.26 (22-72) tuổi. Nguyên nhân chủ yếu là TNGT (chiếm 56,2\%). TNSH: 13 BN (34,2\%), TNTT: 3 BN (7,9\%), TNLĐ: 2 BN (5,3\%). Bên phải bị chấn thương gặp 15/38 BN (39,5\%), bên trái bị chấn thương gặp 23/38 BN (60,5\%).

3.2. Đặc điểm tổn thương. Đau, sưng nề, điểm đau chói cố định, bất lực vận động khớp cổ chân gặp ở 38/38 BN. Dấu hiệu phỏng nước gặp 2/38 BN (chiếm $5,2 \%$ ). Gãy 3 mắt cá chân hay gặp nhất với $20 / 38$ BN chiếm tỷ lệ $52,63 \%$. Gãy 2 mắt cá gặp ở 17/38 BN (44,74\%). 1 BN chỉ gãy mắt cá ngoài. Phân loại theo Lauge - Hansen: $100 \%$ BN đều có cơ chế xoay ngoài, trong đó ngửa - xoay ngoài chiếm $65,8 \%$ và sấp - xoay ngoài chiếm $34,2 \%$. Có 23 BN gãy Weber $B$ $(60,5 \%)$ và $15 \mathrm{BN}$ Weber $\mathrm{C}(39,5 \%)$.

$100 \%$ BN có doãng mộng chày mác và bán trật khớp xương sên ra ngoài trong đó có $20 / 38$ $B N$ có xương sên vừa bán trật khớp ra ngoài vừa 
bán trật khớp ra sau.

$16 / 20$ BN (80\%) có gãy ba mắt cá chân được chỉ định chụp CT Scanner: 16/16 BN có mảnh gãy sau ngoài. Có 2 BN có mảnh gãy rời của MCS kẹt vào khớp chày mác dưới. Có 4 BN có diện tích mảnh gãy $M C S<25 \%$ diện tích bề mặt khớp chày sên. Có $12 / 16$ BN $(75 \%)$ có diện tích mảnh gãy $M C S \geq 25 \%$ diện tích bề mặt khớp chày sên. Phân loại gãy MCS theo Bartonicek thấy chủ yếu gặp loại II với tỉ lệ 50\%.

\subsection{Phương pháp điêu trị}

\subsubsection{Phương pháp kêt hợp xương}

- Mắt cá trong: Kết xương bằng 2 vít xốp $(28 / 37 \mathrm{BN})$, bằng 1 vít xốp $(5 / 37 \mathrm{BN})$ và bằng

1 vít xốp kết hợp 1 đinh Kirschner (1/37BN), bằng 2 vít kết hợp 1 đinh Kirschner (1/37BN), néo ép số 8 (1/37BN).

- Mắt cá ngoài: Có 38/38 BN bị gãy mắt cá ngoài hoặc $1 / 3 \mathrm{D}$ xương mác. trong đó $2 \mathrm{BN}$ được kết xương bằng đinh kirschner do phần mềm xấu, 36 BN kết xương bằng nẹp vít trong đó có 21 BN kết xương bằng nẹp lòng máng, $15 \mathrm{BN}$ kết xương bằng nẹp khóa Kirschner (do gãy thấp ở đầu xương, tuổi cao, gãy phức tạp thân xương mác hoặc mắt cá ngoài).

- Có 20/38 BN bi gãy mắt cá sau, tất cả đều được kết xương bên trong bằng vít xốp, ngoại trừ có 4 BN được kết xương nẹp khóa (do có gãy phức tạp mắt cá sau, người cao tuổi).

3.3.2. Phương pháp cố định khớp chày mác dưới. 25/38 BN được cố định bằng vít xốp, chủ yếu là 1 vít xốp ( $23 \mathrm{BN}$ ) có $2 \mathrm{BN}$ được cố định bằng 2 vít xốp là $2 \mathrm{BN}$ tuổi cao (61 tuổi và 72 tuổi có loãng xương). Có 10/20 BN gãy mắt cá sau (chiếm 50\%) không được cố định khớp chày mác dưới. Có $3 / 18$ không gãy mắt cá sau (chiếm 16,6\%) không được bắt vít cố định mộng chày mác.

\section{4. Đánh giá kết quả}

3.4.1. Kêt quả gần. Có $1 \mathrm{BN}$ bị nhiễm trùng nông vết mổ. $100 \%$ BN có XQ sau mổ đều đạt yêu cầu.

3.4.2. Kết quả xa: Có $34 / 38$ BN khám lại có thời gian sau mổ trên 6 tháng được đánh giá kết quả chức năng theo thang điểm AOFAS. Kết quả: $15 \mathrm{BN}(44,1 \%)$ tốt, $17 \mathrm{BN}(50 \%)$ khá, 2 BN $(5,9 \%)$ trung bình, không có BN có kết quả kém. Điểm trung bình là 91,79 (65-100).

Kết quả XQ: $100 \%$ liền xương các ổ gãy, khớp chày sên về đúng giải phẫu, không doãng mộng chày mác. 2 BN có biểu hiện thoái hóa khớp chày sên, là những BN điều trị thuốc đông $y$ và đến viện muộn sau 14 ngày.

\section{BÀN LUÂ̂N}

4.1. Đặc điểm chung của nhóm nghiên cứu. Nguyên nhân chủ yếu là TNGT (chiếm $56,2 \%)$, trong đó chủ yếu là tai nạn xe máy. Tổn thương 3 mắt cá chân là 20/38 BN (52,63\%). Burwell và Charnley (1965) [1] gặp 13/135 BN có gãy MCS, Ma Ngọc Thành (2010) [5] gặp 11/35 BN và Đỗ Tuấn Anh (2016) [6] gặp 16/55 $B N$. Chúng tôi nhận thấy rằng để chẩn đoán gãy mắt cá chân đơn thuần thì chụp $X Q$ thường quy là đủ xác định. Tuy nhiên nếu có gãy MCS thì nên chụp CTंsanner để xác định được chính xác hình thái, kích thước của mảnh gãy phía sau, phát hiện mảnh gãy nội khớp nhỏ từ đó đưa ra cách tiếp cận và phương pháp cố định thích hợp. Trong nghiên cứu này có $16 / 20$ BN có gãy MCS được chụp CTscanner thì đều có mảnh gãy sau ngoài, 4 BN có mảnh gãy kẹt khớp chày mác dưới mà không thể xác định được trên $X$ quang. Đa số các tác giả khuyên nên chụp CT scanner cổ chân khi có gãy mắt cá sau [4], [5], [6]...

\subsection{Chỉ định và kỹ thuật mổ.}

4.2.1. Kết hợp xương mắt cá trong. Đa số tác giả đều cho rằng, kết xương gãy mắt cá trong thường bằng 2 vít xốp $4.0 \mathrm{~mm}$, nếu mảnh xương gãy nhỏ không thể bắt vít xốp được thì kết xương bằng néo ép số 8 , nếu mảnh xương gãy trung bình thì cố định bằng 1 vít xốp và 1 đinh Kirschner hay chỉ một vít xốp là được. Trong nghiên cứu của chúng tôi có 2 BN có mảnh gãy nhỏ nên được kết hợp xương bằng 1 vít xốp và 1 đinh Kirschner, 1 BN được néo ép số 8 do mảnh gãy quá nhỏ.

4.2.2. Kêt hợp xương mác và mắt cá ngoài. 34/38 BN có gãy 1/3D xương mác hoặc MCN được đánh giá kết quả xa, trong đó

32/34 BN được kêt xương bằng nẹp vít (21 lòng máng, 11 nẹp khóa). Những $B N$ được kết xương bằng nẹp khóa là những $\mathrm{BN}$ tuổi cao loãng xương hoặc có xương mác gãy thấp, gãy phức tạp. Nẹp khóa cho phép cố định vững ổ gãy và tập vận động sớm cổ chân. Kết quả thu được ở các nhóm là tương đương nhau. Có $2 \mathrm{BN}$ bị xây xát da nặng mă̆t ngoài $1 / 3 D$ xương mác nên được kết xương bằng đinh Kirschner, sau mổ BN được cố định bằng bó bột cẳng bàn chân 6 tuần, kết quả chung đêu đạt mức tốt. Một số tác giả thấy rằng đóng đinh nội tủy thường cho kết quả xấu do không chống được di lệch xoay của xương mác. Chúng tôi thấy việc phục hồi giải phẫu MCN là rất quan trọng nhằm mục đích duy trì mối quan hệ chày sên. Khi dùng nẹp vít chúng tôi đảm bảo cố định vững chắc MCN, phục hồi 
được chiều dài xương mác và tránh di lệch xoay. Đây cũng là quan điểm của hiệp hội kết xương AO. Đỗ Tuấn Anh gặp kết quả điều trị tốt và rất tốt chiếm là $80,5 \%$ ở nhóm $B N$ nẹp vít mắt cá ngoài [6].

4.2.3. Kêt hợ xương mắt cá sau. Mặc dù có nhiều hiểu biết về mảnh gãy mắt cá sau ngày càng tăng, vẫn có nhiều tranh luận. Quyết định phẫu thuật cố định MCS theo truyền thống dựa trên kích thước của nó: Các mảnh MCS liên quan đến $>25 \%$ diên tích bề mặt khớp chày sên cần phẫu thuật cố định, các mảnh võ̃ nhỏ hơn thường không cố định. Tuy nhiên các tài liệu gần đây không dựa vào kích thước của MCS để cố định vì thấy rằng điểm AOFAS ở nhóm không kết xương mắt cá sau thấp hơn so với nhóm được kết xương mắt cá sau [7]. Các tác giả khuyển nên cố định tất các trường hợp gãy MCS bất kể kích thước. Mảnh gãy MCS thường là mảnh sau ngoài bao gồm điểm bám của dây chằng chày mác sau dưới, khi gãy MCS dây chẳng này có thường vẫn nguyên vẹn và dính với mảnh võ. Sau khi cố định vững MCS thì sức căng của dây chằng này thường được phục hồi và không cần phải bắt vít cố định mộng chày mác.

Trong nghiên cứu của chúng tôi có 16/34 BN khám lại có gãy MCS, tất cả các BN đều được phẫu thuật bằng đường mổ sau ngoài. 11/16 BN được cố định $\mathrm{MCS}$ bằng vít xốp, $1 \mathrm{BN}$ có mảnh gãy nhỏ được kết hợp bằng 1 vít xốp và 1 đinh Kirschner, 1 BN được kết hợp MCS bằng đinh Kirschner. Đặc biệt có $3 \mathrm{BN}$ do gãy phức tạp MCS, đã được kết hợp bằng nẹp khóa. 15/16 BN có kết quả tốt và khá. Kết quả về chức năng ở nhóm gãy 3 mắt cá và nhóm gãy 2 mắt cá không có sự khác biệt. Điều này cho thấy ưu điểm khi chủ động kết xương mắt cá sau ở tất cả các $B N$.

4.2.4. Vấn đề cố định khớp chày mác dưới. Tất cả $B N$ đều có hình ảnh doãng mộng chày mác trên $X Q .2 \mathrm{BN}$ được cố định khớp chày mác dưới bằng 2 vít xốp, $20 \mathrm{BN}$ được cố định bằng 1 vít xốp. Các vít xốp đều được bắt qua 4 thành xương, 12 BN không bắt vít cố định, đây là những BN có Test Cotton (-) sau khi cố định gãy xương mác và mắt cá sau (nếu có). Vít được tháo sau mổ 8-10 tuần. Kết quả thu được ở các nhóm có bắt vít và không bắt vít cố định khớp chày mác dưới không có sự khác biệt.

Hiện nay phương pháp bắt vít để cố định khớp chày mác dưới vẫn còn nhiều tranh luận như: vị trí đặt vít, số vỏ xương và đường kính vít, tháo vít hay không tháo vít? Mc.Bryde (1997) cho rằng nên sử dụng vít $3.5 \mathrm{~mm}$, bắt vít trên mặt khớp chày sên $2 \mathrm{~cm}$. Theo Kukreti (2005) vị trí đặt vít tốt nhất là trên mặt khớp chày sên 2-5 $\mathrm{cm}$. Thompson (2000) không tìm thấy sự khác biệt về cơ sinh học khi cố định khớp chày mác dưới bằng 1 vít $3.5 \mathrm{~mm}$ so với 1 vít $4.5 \mathrm{~mm}$. Một số tác giả gần đây không ủng hộ thói quen tháo vít cố định khớp chày mác dưới vì thấy kết quả không khác biệt khi vít được giữ lại và tháo ra. Tuy nhiên, một nghiên cứu cho thây kết quả chức năng được cải thiện ở những BN bị gãy, nới lỏng hoặc tháo vít so với những $B N$ còn nguyên vít [8]. Đây có thể được coi là một gợi ý về việc không nên bỏ qua việc tháo vít cố định mộng chày mác.

\subsection{Kết quả gân}

4.3.1. Phục hồi giải phẫu khớp. $38 / 38 \mathrm{BN}$ (100\%) có XQ sau phẫu thuật đều đạt yêu cầu giải phẫu. Chúng tôi không ghi nhận được trường hợp nào chụp XQ cổ chân sau mổ không đạt giải phẫu, hoặc có vít bắt vào diện khớp. Kết quả này cũng tương đồng với Ma Ngọc Thành, Đỗ Tuấn Anh [5], [6].

4.3.2. Liền da và nhiễm trùng sau mổ. $37 / 38 \mathrm{BN}(97,3 \%)$ liền da thì đầu, chỉ có $1 \mathrm{BN}$ nhiễm khuẩn nông vết mổ xương mác sau mổ 5 ngày, BN đã được cắt lọc, thay băng và dùng kháng sinh điều trị, sau đó vết mổ liền tốt. Kết quả này cũng phù hợp với Ma Ngọc Thành [5], Đỗ Tuấn Anh [6]. Vijay Karande [3]. Chúng tôi cho rằng một trong các yếu tố để hạn chế nhiễm khuẩn vết mổ là nên lựa chọn thời điểm phẫu thuật phù hợp.

4.4. Kết quả xa. Có $34 / 38$ BN được đánh giá theo thang điểm AOFAS với thời gian theo dõi trung bình là 21,3 tháng. Điểm trung bình là 91,79 (65-100). Kết quả Tốt: 15 BN $(44,1 \%)$, Khá: 17 BN (50\%); Trung bình: 2 BN (5,9\%); Xấu: 0 BN. Trong đó tốt và khá chiếm $94,1 \%$; cao hơn so với Burwell [1](82\%), Vijay Karande [3] $(86,2 \%)$, Ma Ngọc Thành [5] $(80,65 \%)$, Đỗ Tuấn Anh [6] (82,7\%). Chúng tôi có 02 BN xếp loại xấu là 2 BN gãy kiểu Weber $B, C$, bị tiểu đường, cao tuổi, phâuu thuật muộn sau khi điều trị bằng thuốc đông $\mathrm{y}$. XQ cho thấy các ổ gãy đều liền xương nhưng có biểu hiện thoái hóa khớp cổ chân.

\section{KẾT LUÂ̂N}

- Thời gian nằm viện trung bình là 8,05 ngày. $37 / 38 \mathrm{BN}(97,3 \%)$ BN liền da thì đâu. $1 \mathrm{BN}$ có nhiễm khuẩn nông, liền da thì 2. $100 \% \mathrm{BN}$ có hình ảnh $X Q$ đạt giải phẫu sau mổ.

- 34/38 BN được theo dõi tối thiểu là 6 tháng. Điểm AOFAS trung bình là 91,79 (65-100). Tốt 15 BN (44,1\%), Khá 17 BN (50\%), trung bình 2 
BN $(5,9 \%)$, Xấu 0 BN.

- 32/34 BN (94,1\%) liền xương các ổ gãy, khớp chày sên về đúng vị trí giải phẫu, không doãng mộng chày mác. Có 2 BN $(5,9 \%)$ thoái hóa khớp chày sên.

- Gãy mắt cá sau di lệch nên được nắn chỉnh và cố định vững chắc bằng vít xốp hoặc nẹp vít với đường mổ sau ngoài hoặc sau trong. Nên kết xương mác, mắt cá sau (nểu có) rôi đến mắt cá trong. Bắt vít cố định mộng chày mác được chỉ định khi test Cotton $(+)$.

- Điều trị bằng phấu thuật nắn chỉnh mở và kết hợp xương bên trong giúp BN gãy Dupuytren phục hồi được giải phẫu và chức năng cổ chân, đặc biệt khi kèm gãy mắt cá sau.

\section{TÀl LIẸU THAM KHẢO}

1. Burwell H.N. và Charnley A.D. (1965). The treatment of displaced fractures at the ankle by rigid internal fixation and early joint movement. J Bone Joint Surg Br, 47(4), 634-660.
2. Verhage S. (2019), Management of the posterior malleolus in trimalleolar fractures. 179, Leiden University, the Netherlands.

3. Karande V., Nikumbha V.P., Desai A. el all. (2017), "Study of surgical management of malleolar fractures of ankle in adults", Int J Orthop Sci, 3(3), 783-787.

4. Bartoníček J., Rammelt S., Tuček M. el all. (2015), "Posterior malleolar fractures of the ankle", Eur J Trauma Emerg Surg, 41(6), 587-600.

5. Ma Ngọc Thành (2010), Đánh giá kết quả phẫu thuâtt gã̃y kín mắt cá chân tại bệnh viện hữu nghị Việt Đức, Luận văn thạc sĩ y học đaji học y Hà Nội.

6. Đồ Tuấn Anh (2016). Kết quả phầu thuật gãy kín xương mắt cá chân ở người trướng thành tại bênh viện Hữu nghị Việt Đức. Luận văn thạc sĩ y học đại hợc y Hà Nối.

7. Tosun B., Selek O., Gok U. et all. (2018) "Posterior Malleolus Fractures in Trimalleolar Ankle Fractures: Malleolus versus Transyndesmal Fixation". Indian J Orthop, 52(3), 309-314.

8. Mak M.F., Stern R., Assal M.' (2018). "Repair of syndesmosis injury in ankle fractures". EFORT Open Rev, 3(1), 24-29.

\section{ĐÁNH GIÁ THỰC TRANG TỔN THƯƠNG THÂN CẤP THEO THANG ĐIỂM RIFLE Ở BÊNHH NHÂN ĐIỀU TRI TẠI KHOA HỒI SỨC TÍCH CỰC VÀ CHỐNG ĐộC}

\section{TÓM TẮT ${ }^{3}$}

Mục tiêu: Phân tích đặc điểm, các yếu tỗ nguy cơ và tiên lượng tử vong của bệnh nhân tôn thương thận cấp. Đối tượng và phương pháp: 201 bệnh nhẩn điều trị tại khoa Hồi sức tích cực và Chống độc từ tháng 03 đến tháng 09 năm 2020. Tiến cứu mô tả. Kết quả: Tuổi TB 80.1; $84.1 \%$ là nam, ngày điều trị ICU TB 14.6, tỉ lệ TV gấp 3.6 lần ở nhóm AKI so với NAKI.Tỷ lệ AKI 34.3\%; mắc mới $19.4 \%$; hồi phục $31.9 \%$; tử vong: $40.6 \%$. Nguyên nhân: sốc nhiếm khuẩn $(52.2 \%)$, thiếu dịch $(14.5 \%)$, suy tim $(13 \%)$, thuốc độc với thận $(8.7 \%)$. Các yếu tố nguy cơ AKI: suy đa tạng (OR 6.8), sốc (OR 4.6), nhiễm khuẩn nặng (OR 3.2). Nguy cơ tử vong: sốc (OR 13.0), suy đa tang (OR 11.3), phải thở máy (OR 8.4), suy gan, rối loạn đông máu (OR 4.4). AKI thời điểm nặng nhất liên quan đển tỷ lề tử vong: R (OR 2.3), I (OR 3.7), $\mathrm{F}(\mathrm{OR}$ 4.5). Sốc nhiễm khuân làm tăng tử vong ở bệnh nhân AKI lên 3.5 lần $(p<0.05)$, suy tim là 2.6 lần $(p<0.05)$ và dùng thuốc độc với thận là 1.5 lần $(p<0.05)$ so với nhóm NAKI. Kết luận: Phân độ RIFLE

*Bênh viên Hữu Nghi

Chịu trách nhiệm chính: Tô Hoàng Dương

Email: dr.hoangduong@gmail.com

Ngày nhận bài: 22/8/2021

Ngày phản biên khoa hoc: 17/9/2021

Ngày duyệt bài: 2/10/2021

\section{Nguyễn Thế Anh*, Tô Hoàng Dương*}

đơn giản, áp dụng tốt tại các đơn vị hồi sức để đánh giá mức độ, tiến triển của tổn thương thận cấp.

Tư khóa: Đặc điểm, yếu tố nguy cớ, tiên lượng tử vong, tổn thương thận cấp.

\section{SUMMARY \\ ASSESSMENT OF THE CURRENT SITUATION OF ACUTE KIDNEY INJURY BY RIFLE SCOPE INPATIENTS TREATED AT CRITICAL CARE AND POISONING CONTROL DEPARTMENT}

Objectives: To analyze the characteristics, risk factors and mortality prognosis of patients with acute kidney injury. Subjects and method: 201 patients treated at the critical care and poisoning control department from March to September 2020. Descriptive prospective. Results: Average age 80.1; $84.1 \%$ were male, the ICU treatment day was 14.6 , the rate of mortality was 3.6 times higher in the AKI group than in the NAKI group. The rate of AKI was $34.3 \%$; $19.4 \%$ new cases; recovered $31.9 \%$; mortality: $40.6 \%$. Causes: septic shock (52.2\%), fluid deficiency $(14.5 \%)$, heart failure $(13 \%)$, nephrotoxic drugs $(8.7 \%)$. Risk factors for AKI: multiple organ failure (OR 6.8), shock (OR 4.6), severe infection (OR 3.2). Risk of death: shock (OR 13.0), multiple organ failure (OR 11.3), mechanical ventilation (OR 8.4), liver failure, coagulopathy (OR 4.4). The most severe AKI was associated with mortality: R (OR 2.3), I (OR 